
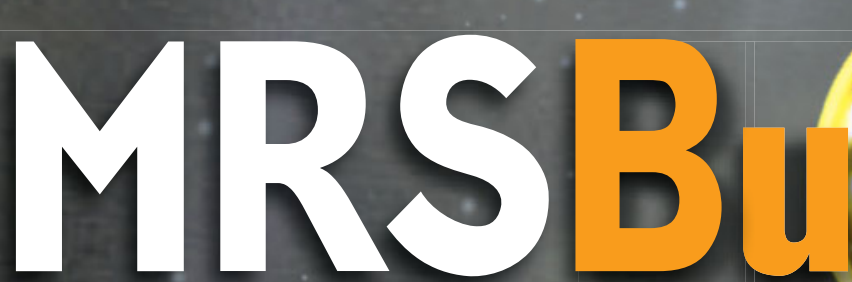

\title{
$\mathrm{M}|\mathrm{R}| \mathrm{S}$
}

MATERIALS RESEARCH SOCIETY

Advancing materials. Improving the quality of life.

\section{Organic spintronics}
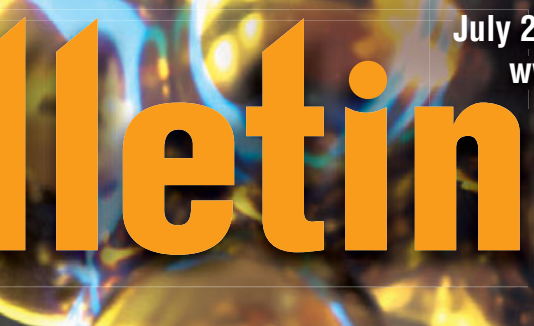

uly 2014 Vol. 39 No. 7

www.mrs. org/bulletin
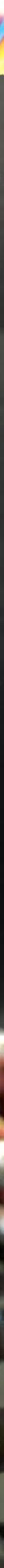


\section{CUSTOMIZED PRODUCTION ION IMPLANTERS}

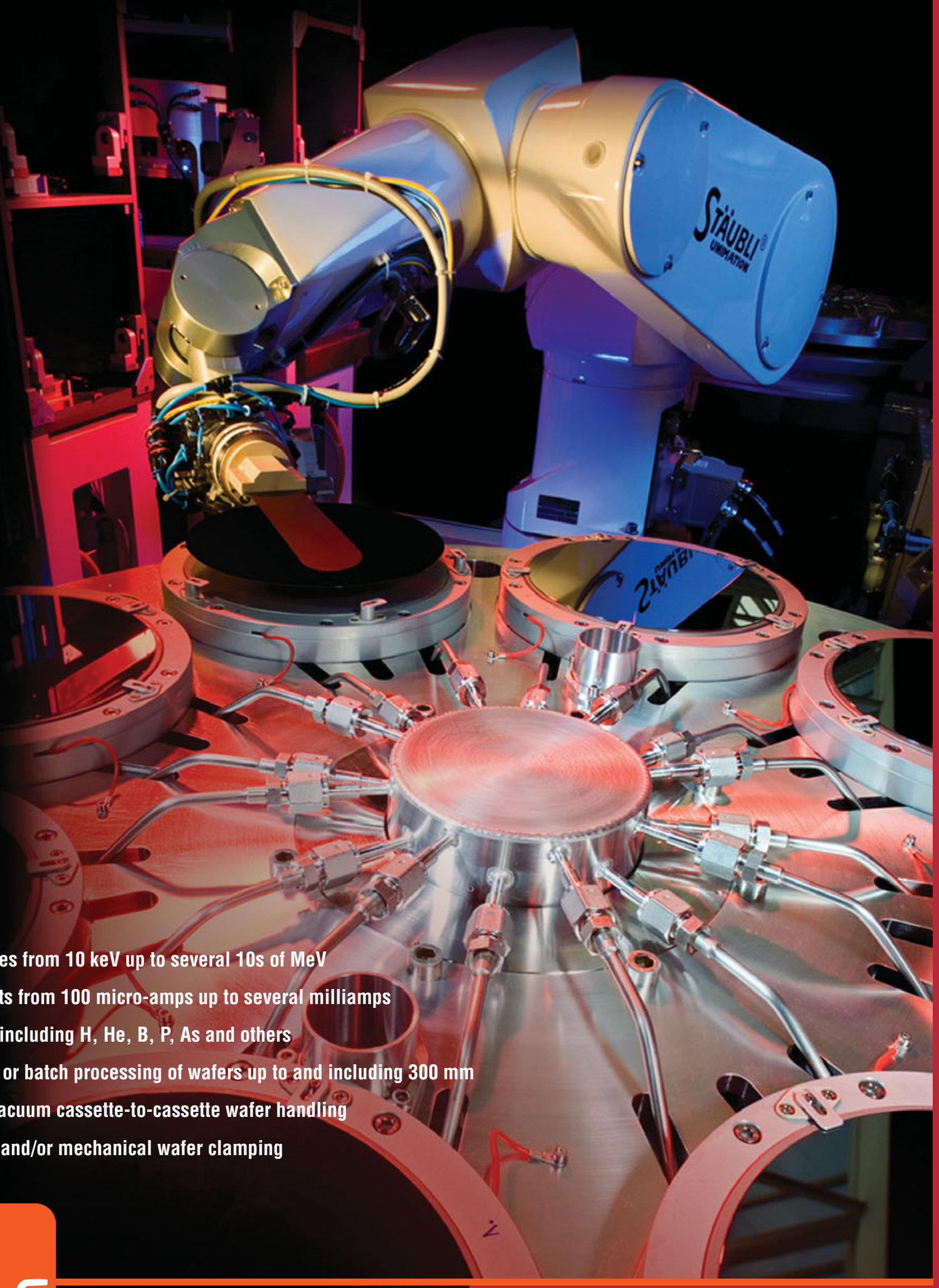

Beam energies from $10 \mathrm{keV}$ up to several 10 s of MeV

- Beam currents from 100 micro-amps up to several milliamps

Ion species, including H, He, B, P, As and others

Single wafer or batch processing of wafers up to and including $300 \mathrm{~mm}$

In-air or in-vacuum cassette-to-cassette wafer handling

Electrostatic and/or mechanical wafer clamping

\section{High Voltage Engineering}

High Voltage Engineering Europa B.V.

P.O. Box 99, 3800 AB Amersfoort, The Netherlands Tel: $31334619741 \cdot$ info@highvolteng.com 


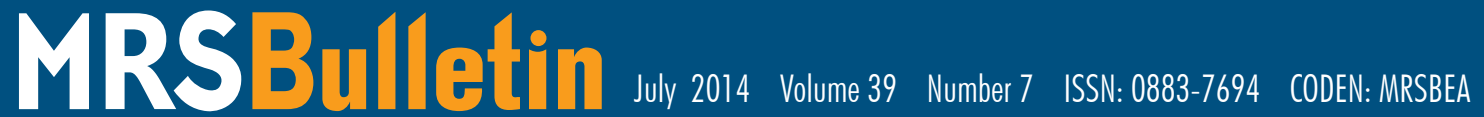
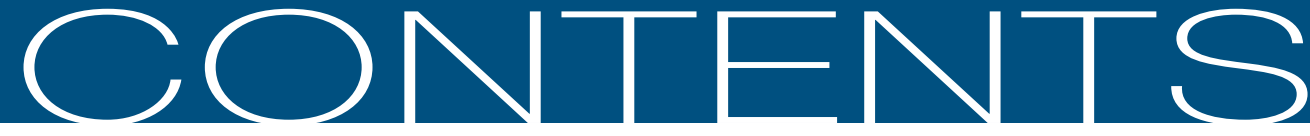

\section{ORGANIC SPINTRONICS}

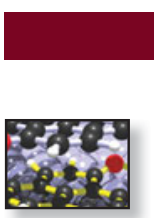

578 On the path toward organic spintronics Jagadeesh S. Moodera, Bert Koopmans, and Peter M. Oppeneer, Guest Editors

\section{Meet Our Authors}

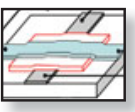

585 The development of organic spin valves from unipolar to bipolar operation

Tho D. Nguyen, Eitan Ehrenfreund, and Z. Valy Vardeny

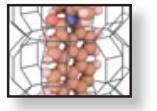

590 Intrinsic magnetic field effects in organic semiconductors

Markus Wohlgenannt, Peter A. Bobbert, and Bert Koopmans

596 Interface-assisted spintronics: Tailoring at the molecular scale

Nicolae Atodiresei and Karthik V. Raman

602 Spinterface: Crafting spintronics at the molecular scale

Marta Galbiati, Sergio Tatay, Clément Barraud, Alek V. Dediu, Frédéric Petroff, Richard Mattana, and Pierre Seneor

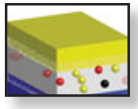

608 Spin-resolved imaging and spectroscopy of individual molecules with sub-molecular spatial resolution Jens Brede and Roland Wiesendanger

614 Computational design of magnetic metal-organic complexes and coordination polymers with spin-switchable functionalities Tanusri Saha-Dasgupta and Peter M. Oppeneer

\section{TECHNICAL FEATURE}

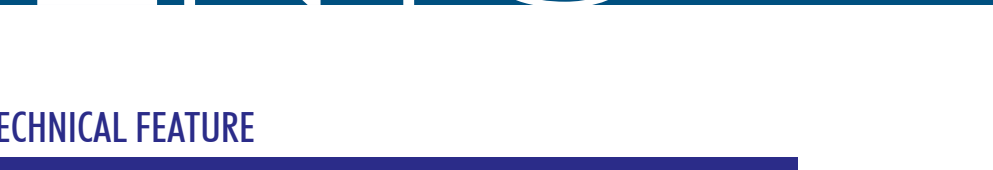

\section{DEPARTMENTS}

621 Biocompatible ultrananocrystalline diamond coatings for implantable medical devices Orlando Auciello, Pablo Gurman, Maria B. Guglielmotti, Daniel G. Olmedo, Alejandro Berra, and Mario J. Saravia

\section{$\stackrel{\sim}{\Rightarrow}$ OPINION}

565 Letter from the President Advancing the MRS Mission through the Materials Research Society Foundation Tia Benson Tolle

567 Material Matters

Materials science in the Anthropocene: MRS gets serious about sustainable development Martin L. Green

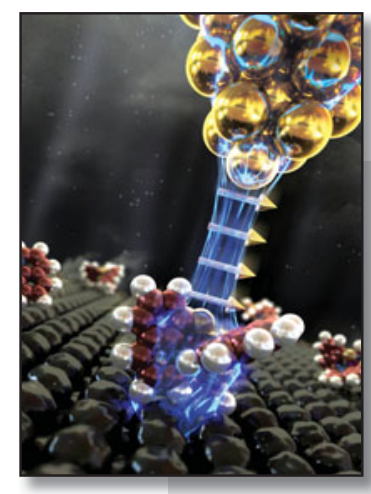

\section{ON THE COVER}

Organic spintronics. Organic materials represent a new and unique platform for exploiting the spin of the electron that can lead to organic spintronics. This issue of MRS Bulletin introduces the possibilities for spin functionalities that are encompassed in molecular materials. Spin-dependent properties of molecular materials can be controlled and investigated in many different ways, as discussed in the articles in this issue. The image on the cover shows one example: spin-polarized scanning tunneling microscopy (STM) on a single molecule. Several molecules are bonded to a surface, where spin-split states are probed by polarized current from the STM tip. See the technical theme that begins on page 578 . 


\section{- NEWS \& ANALYSIS}

\section{Materials News}

- Taking heart in gelatin for tissue engineering Lukmaan A. Bawazer

- Electrical control benefits nuclear spin qubits

- High conductivity supercapacitors achieved with graphene nanocomposites Jean L. Njoroge

- Feather microstructure leads to reduced friction surfaces Mary Nora Dickson

- C.N.R. Rao receives Bharat Ratna Award

- Stuart Parkin receives 2014 Millennium Technology Prize for opening big data era

- Kavli Prize in Nanoscience goes to Ebbesen, Hell, and Pendry

\section{Science Policy}

- Next-generation nuclear power in the UK: A challenge but not an impossibility Angela Saini

- DOE releases report on hydropower

\section{FEATURES}

\section{Books}

- Hydrogen Storage Technology:

Materials and Applications

Lennie Klebanoff, Editor

Reviewed by N. Balasubramanian

- Carbon Nanotube and Graphene Device Physics H.-S. Philip Wong and Deji Akinwande Reviewed by Dieter Vollath

- Biomimetics in Photonics Olaf Karthaus, Editor Reviewed by Nirmal Govindaraju

\section{Posterminaries}

Subject: Posterminaries-thank you for your consideration

\section{SOCIETY NEWS}

- 2014 Materials Research Society Spring Meeting shows where research meets industry

- Preview: XXIII International Materials Research Congress 2014

- Linda S. Schadler appointed JMR Associate Editor, Polymers and Organic Materials

- MRS seeks award nominations for $\mathbf{2 0 1 5}$

- YUCOMAT 2014 to be held in September 2014 in Montenegro

- 2nd International Conference on Bioinspired and Biobased Chemistry \& Materials to be held in October 2014 in France

\section{CAREER CENTRAL}

\section{ADVERTISERS IN THIS ISSUE}

Aldrich Materials Science

American Elements

Furuya Metal Americas, Inc.

High Voltage Engineering ....................... Inside front cover Hindawi Publishing Corporation ............ Inside back cover Janis Research Company, Inc. ....................................581 JEOL USA, Inc. .......................................................... 577

Kurt J. Lesker Company ...............................................5 574

National Electrostatics Corporation …........................584

Rigaku Corporation .................................................. 589

\section{www.mrs.org/bulletin}

MRS members-access MRS Bulletin online

www.mrs.org/energy-quarterly

Access Energy Quarterly online

www.mrs.org/mymrs

MRS Publications Alert-

receive advance Table of Contents by email

http://journals.cambridge.org/ mrsbulletin-rss

Subscribe TODAY to the MRS Bulletin RSS Feed 


\section{$\mathrm{M}|\mathrm{R}| \mathrm{S}$}

MATERIALS RESEARCH SOCIETY ${ }^{\circledR}$

Advancing materials. Improving the quality of life.
EDITORIAL OFFICE 506 Keystone Drive, Warrendale, PA 15086-7573 USA Bulletin@mrs.org tel 724.779.2747 fax 724.779.8313 www.mrs.org

\section{About the Materials Research Society}

The Materials Research Society (MRS), a not-for-profit scientific association founded in 1973 and headquartered in Warrendale, Pennsylvania, USA, promotes interdisciplinary materials research. Today, MRS is a growing, vibrant, member-driven organization of over 16,000 materials researchers spanning over 80 countries, from academia, industry, and government, and a recognized leader in the advancement of interdisciplinary materials research.

The Society's interdisciplinary approach differs from that of single-discipline professional societies because it promotes information exchange across many scientific and technical fields touching materials development. MRS conducts three major international annual meetings encompassing approximately 125 topical symposia, and also sponsors numerous single-topic scientific meetings. The Society recognizes professional and technical excellence and fosters technical interaction through University Chapters. In the international arena, MRS implements bilateral projects with partner organizations to benefit the worldwide materials community. The Materials Research Society Foundation helps the Society advance its mission by supporting various projects and initiatives.

MRS publishes MRS Bulletin, MRS Communications, the MRS Online Proceedings Library, Journal of Materials Research, MRS Energy \& Sustainability, and books and textbooks with its publishing partner, Cambridge University Press.

\section{MRS BOARD OF DIRECTORS}

President Tia Benson Tolle, The Boeing Company, USA Immediate Past President Orlando Auciello, University of Texas at Dallas, USA

Vice President and President-Elect Oliver Kraft, Karlsruhe Institute of Technology, Germany

Secretary Sean J. Hearne, Sandia National Laboratories, USA

Treasurer Michael R. Fitzsimmons, Los Alamos National Laboratory, USA

Executive Director Todd M. Osman, Materials Research Society, USA

Shenda M. Baker, Synedgen, Inc./Harvey Mudd College, USA

Alexandra Boltasseva, Purdue University, USA

C. Jeffrey Brinker, Sandia National Laboratories and University

of New Mexico, USA

David Cahen, Weizmann Institute of Science, Israel

Steve Eglash, Stanford University, USA

Chang-Beom Eom, University of Wisconsin-Madison, USA

Susan Ermer, Lockheed Martin Advanced Technology Center, USA

Eric Garfunkel, Rutgers University, USA

Sossina M. Haile, California Institute of Technology, USA

Andrea M. Hodge, University of Southern California, USA

Hideo Hosono, Tokyo Institute of Technology, Japan

Fiona C. Meldrum, University of Leeds, UK

Kornelius Nielsch, University of Hamburg, Germany

Eric A. Stach, Brookhaven National Laboratory, USA

Stephen Streiffer, Argonne National Laboratory, USA

Loucas Tsakalakos, General Electric-Global Research Center, USA

\section{MRS OPERATING COMMITTEE CHAIRS}

Academic Affairs Bruce Clemens, Stanford University, USA

Awards C. Barry Carter, University of Connecticut, USA

Government Affairs Nabil Bassim, US Naval Research Laboratory, USA

Meetings Committee David S. Ginley, National Renewable Energy Laboratory, USA

Member Engagement Yves Chabal, University of Texas at Dallas, USA

Public Outreach Aditi Risbud, University of Utah in Salt Lake City, USA

Publications Susan Trolier-McKinstry (Acting Chair), The Pennsylvania State

University, USA

MRS OFFICE OF PUBLIC AFFAIRS

Ron Kelley 499 South Capitol St. SW, Suite 600, Washington, DC 20003
Editor

Gopal R. Rao, rao@mrs.org

Managing Editor

Judy Meiksin, meiksin@mrs.org

Technical Editor

Lori A. Wilson, Iwilson@mrs.org

Editorial Assistants

Michelle S. Raley, raley@mrs.org

Mary Wilmoth

Associate Technical Editor

Carol Tseng

Production/Design

Andrea Pekelnicky, Felicia Turano,

Rebecca Yokum, and TNQ

Production Editor

Catherine Paduani

Science News Editor

Tim Palucka

Principal Development Editor

Elizabeth L. Fleischer

Director of Communications

Eileen Kiley Novak

\section{Guest Editors}

Jagadeesh S. Moodera, Bert Koopmans, and Peter M. Oppeneer

Special Contributors Justin Bours, Ryan Cloke, and Boris Dyatkin

Energy Quarterly Anke Weidenkaff (Chair) Anshu Bharadwaj, David Cahen, Russell R. Chianelli, George Crabtree, Sabrina Sartori, M. Stanley Whittingham, and Steve M. Yalisove

Advertising/Sponsorship Mary E. Kaufold, kaufold@mrs.org Donna L. Watterson, watterson@mrs.org

Member Subscriptions

Michelle Judt, judt@mrs.org

Non-Member Subscriptions subscriptions_newyork@cambridge.org

\section{EDITORIAL BOARD}

Paul S. Drzaic (Chair), Apple, Inc., USA

V.S. Arunachalam, Center for Study of Science, Technology \& Policy, India Hanns-Ulrich Habermeier, Max Planck Institute for Solid State Research, Germany Igor Lubomirsky, Weizmann Institute, Israel

Fiona C. Meldrum, University of Leeds, UK

Amit Misra, University of Michigan, USA

Steven C. Moss, Aerospace Corporation, USA

Julie A. Nucci, Cornell University, USA

Linda J. Olafsen, Baylor University, USA

James W. Stasiak, Hewlett-Packard Co., USA

Carol Trager-Cowan, University of Strathclyde, UK

Anke Weidenkaff, University of Stuttgart, Germany

Eric Werwa, Washington, DC, USA

Steve M. Yalisove, University of Michigan, USA

\section{VOLUME ORGANIZERS}

2015 Ying-Hao (Eddie) Chu, National Chiao Tung University, Taiwan Kalpana S. Katti, North Dakota State University, USA Tommie W. Kelley, 3M, USA Jud Ready, Georgia Institute of Technology, USA

2014 Deborah E. Leckband, University of Illinois at Urbana-Champaign, USA Yuri Suzuki, Stanford University, USA

Enrico Traversa, King Abdullah University of Science and Technology, Saudi Arabia Yonhua Tzeng, National Cheng Kung University, Taiwan

2013 Mark T. Lusk, Colorado School of Mines, USA Eva Olsson, Chalmers University of Technology, Sweden Birgit Schwenzer, Pacific Northwest National Laboratory, USA James W. Stasiak, Hewlett-Packard Co., USA

MRS Bulletin (ISSN: 0883-7694, print; ISSN 1938-1425, online) is published monthly by the Materials Research Society, 506 Keystone Drive, Warrendale, PA 15086-7573. Copyright @ 2014 Materials Research Society. Permission required to reproduce content. Periodical postage paid at New York, NY, and at additional mailing offices. POSTMASTER: Send address changes to MRS Bulletin in care of the Journals Department, Cambridge University Press, 100 Brook Hill Drive, West Nyack, NY 10994-2113, USA. Printed in the U.S.A.

Membership in MRS is $\$ 115$ annually for regular members, $\$ 30$ for students. Dues include an allocation of $\$ 29$ ( $\$ 17$ for students) to a subscription to MRS Bulletin. Individual member subscriptions are for personal use only. Non-member subscription rates are $\$ 439$ for one calendar year (12 issues) within North America and $\$ 527$ elsewhere. Requests from subscribers for missing journal issues will be honored without charge only if received within six months of the issue's actual date of publication.

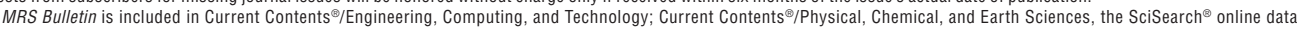
ase, Research Alert ${ }^{\oplus}$ Science Citation Index ${ }^{\circledast}$ and the Materials Science Citation Index 300 North Zeeb Road, Ann Arbor, MI 48106, USA.
Send Letters to the Editor to Bulletin@mrs.org. Include your name, affiliation, and full contact information. 